\title{
Comprehensive two-dimensional gas chromatography time of flight mass spectrometry (GC $\times$ GC-TOFMS) for environmental forensic investigations in developing countries
}

\author{
Jayne de Vos $^{\mathrm{a}, *}$, Roger Dixon ${ }^{\mathrm{b}, 1}$, Gerhard Vermeulen ${ }^{\mathrm{b}, 1}$, Peter Gorst-Allman ${ }^{\mathrm{c}, 2}$, Jack Cochran ${ }^{\mathrm{d}, 3}$, \\ Egmont Rohwer ${ }^{\mathrm{e}, 4}$, Jean-Francois Focant ${ }^{\mathrm{f}, 5}$ \\ a Organic and Bio-Analysis Group, Metrology in Chemistry Area, National Metrology Institute of South Africa, Private Bag X34, Lynnwood Ridge 0040, South Africa \\ ${ }^{\mathrm{b}}$ South African Police Services Forensic Science Laboratory, Silverton, South Africa \\ c LECO Africa Pty Ltd., P.O. Box 1439, Kempton Park 1620, South Africa \\ ${ }^{\mathrm{d}}$ Restek Corporation, 110 Benner Circle, Bellefonte, PA, USA \\ e Department of Chemistry and Agriculture, University of Pretoria, Pretoria, South Africa \\ ${ }^{\mathrm{f}}$ Mass Spectrometry Laboratory, Biological and Organic Analytical Chemistry, University of Liège, Allée du 6 août, B6c, B-4000 Liège (Sart-Tilman), Belgium
}

\section{A R T I C L E I N F O}

\section{Article history:}

Received 7 July 2010

Received in revised form 11 November 2010

Accepted 7 December 2010

Available online $\mathrm{xxxx}$

\section{Keywords:}

Environmental pollutants

PCDDs

PCDFs

PCBs

PAHs

Dioxin quantitation

Forensic

\begin{abstract}
A B S T R A C T
The disposal and dumping of toxic waste is a matter of growing concern in developing countries, including South Africa. Frequently these countries do not possess access to gas chromatography-high resolution mass spectrometry (GC-HRMS) for the determination of persistent organic pollutants (POPs). This publication describes an alternative approach to the investigation of toxic waste using comprehensive gas chromatography coupled to time of flight mass spectrometry (GC $\times$ GC-TOFMS). The technology permits both comprehensive screening of toxic samples for numerous classes of organic pollutants and also quantitative analysis for the individual compounds. This paper describes the use of this technique by analysing samples obtained from a hazardous waste treatment facility in South Africa. After sampling and extraction the samples were analysed for polychlorinated dibenzo-p-dioxins (PCDDs), polychlorinated dibenzofurans (PCDFs) and four dioxin-like non-ortho substituted polychlorinated biphenyls (PCBs). The quantitative values, as well as detection limits, obtained using the GC $\times$ GC-TOFMS methodology compares well with those obtained using GC-HRMS; the accepted benchmark technology for this analysis. Although GC $\times$ GC-TOFMS is not a target compound analytical technique (as is GC-HRMS), it is possible to obtain information on numerous other classes of organic pollutants present in the samples in one analytical run. This is not possible with GC-HRMS. Several different column combinations have been investigated for handling very complex waste samples and suggestions are presented for the most suitable combination.
\end{abstract}

(c) 2010 Elsevier Ltd. All rights reserved.

\section{Introduction}

The disposal of toxic waste is of enormous concern to authorities in developing countries. Facilities are not as rigorous or as well maintained as those in more developed countries, and poorer countries are sometimes driven to import toxic waste for disposal

\footnotetext{
* Corresponding author. Tel.: +2786 6181621.

E-mail addresses: bjdevos@nmisa.org (J. de Vos), dixonr@saps.org.za (R. Dixon), vermeuleng@saps.org.za (G. Vermeulen), peter@lecoafrica.co.za (P. Gorst-Allman), jack.cochran@restek.com (J. Cochran), egmont.rohwer@up.ac.za (E. Rohwer), jf. focant@ulg.ac.be (J.-F. Focant).

1 Tel.: +27 128455915 .

2 Tel.: +2786 6786226 .

3 Tel.: +18143531309.

4 Tel.: +27 123625297 .

5 Tel.: +3243664387.
}

as a means of raising revenue (Birnbaum and de Vito, 1995; Schecter et al., 2006). Monitoring procedures and methods are generally poor and legal controls are not in place to govern disposal and handling. This allows unscrupulous operators to profit by waste disposal that is criminally negligent. The Forensic Science Laboratory of the South African Police Services has investigated a number of cases involving hazardous and toxic waste dumping and disposal in South Africa.

This paper describes the use GC $\times$ GC-TOFMS (Commission Regulation 1881, 2006; Korytár, 2006; Semard et al., 2009) for the qualitative analysis of priority pollutants of environmental concern, and the specific quantitation of PCDDs, PCDFs and dioxin-like non-ortho substituted PCB compounds in hazardous waste. Selectivity, sensitivity and detection limits are addressed in a subsequent paper submitted for publication (de Vos et al., submitted for publication).

0045-6535/\$ - see front matter (c) 2010 Elsevier Ltd. All rights reserved. doi: $10.1016 /$ j.chemosphere.2010.12.039 
In developing countries, methodology and equipment for GCHRMS (EPA Method 1613, 1994; Eppe et al., 2004; Reiner et al., 2006) for the determination of POPs is frequently not in place (Focant et al., 2001a). In South Africa there is no established facility capable of routine GC-HRMS determinations of POPs and especially PCDD/F analysis (Batterman et al., 2009). An alternative approach using GC $\times$ GC-TOFMS, an emerging technology that can be used to analyse complex samples, has been implemented (Focant et al., 2004a,b,c,d,e; Reiner et al., 2006).

Comprehensive GC $\times$ GC is a technique in which two GC columns using different modes of separation are connected together in series. Between the two columns is a thermal modulator (Dimandja et al., 2003; Focant et al., 2003, 2004c; Semard et al., 2009) which traps portions of eluent from the first column and re-injects them onto the second column. This process occurs repeatedly, thus all the compounds from the sample are subjected to two distinct separations, resulting in a separation superior to that possible on a ${ }^{1}$ D GC system (Schoenmakers et al., 2003), with many more compounds resolved as a result of the multiplicative increase in peak separation number. In addition, the sensitivity of the GC $\times$ GC system is also improved approximately 10 -fold relative to ${ }^{1} \mathrm{D}$ GC by the focusing effect of the modulator (Korytár, 2006; Semard et al., 2009).

GC $\times$ GC-TOFMS is unique in being the only technique that has the ability to detect all the compounds of complex samples at the levels needed for priority pollutant determination in a single analysis. It can provide rapid and comprehensive determination of whether a sample contains compounds harmful to human and animal health. Positive samples can then be sent for quantitative analysis using the reference GC-HRMS technique (Eppe et al., 2004; Reiner et al., 2006). The costs associated in analysing negative samples would then not be incurred.

GC $\times$ GC-TOFMS can also be used to obtain quantitative data, and is capable of reaching the levels stipulated in Environmental Protection Agency (EPA) Method 1613 (1994) for the quantitation of the 17 PCDDs and PCDFs (Focant et al., 2004c; Hoh et al., 2007). The results obtained by GC $\times$ GC-TOFMS for the quantitation of these compounds in the samples (described in Section 3.3) were compared with results obtained for the same sample set using GC-HRMS to confirm the validity of the quantitation, as this is the first time such a comprehensive environmental screening and PCDD determination has been done in South Africa using $\mathrm{GC} \times$ GC-TOFMS.

PCDDs and PCDFs are well-known anthropogenic compounds formed as by-products during combustion processes used in waste disposal. 2,3,7,8-Tetrachlorodibenzo-p-dioxin (2,3,7,8-TeCDD: $\mathrm{Te}=$ tetra, $\mathrm{Pe}=$ penta, $\mathrm{Hx}=$ hexa, $\mathrm{Hp}=$ hepta) has been determined as the most toxic man-made chemical (Pereira, 2004) and methods for the determination of this compound, along with 16 other chlorinated PCDD/Fs, are described in EPA Method 1613 (1994) and in European Method EN-1948 (1996).

The toxicity of the compounds making up this set is defined in terms of the toxic equivalency factor (TEF) (van den Berg et al., 2006). The 2,3,7,8-TeCDD congener is assigned a value of one, and the other compounds are related to it by measuring their relative toxicity. The total toxic equivalency (TEQ) value is calculated from the sum of the individual toxic equivalency factors (TEFs) for all 17 PCDD/F congeners. The contribution of each congener to the total value has to be established and it is therefore essential to separate the $17 \mathrm{PCDD} / \mathrm{F}$ congeners from each other, especially the seven hexachlorodibenzo- $p$-dioxins and furans (HxCDD/Fs).

The cost and sophistication of GC-HRMS is of concern in developing countries, including South Africa. GC $\times$ GC-TOFMS was selected as an alternative quantitative technique having been used previously for PCDD/F analysis, though little attention has been focussed on combining the accurate quantitative capability of GC $\times$ GC-TOFMS with broad level priority pollutant screening.

\section{Experimental}

\subsection{Chemicals}

For the sample extraction and GC-HRMS analyses, all solvents used were Pestanal reagents (Riedel-de Haën, Seelze, Germany). Nonane, Puriss analytical-reagent grade standard for GC, was purchased from Fluka (Steinheim, Germany). Sodium sulfate anhydrous was Baker-analyzed (J.T. Baker, Deventer, Netherlands). Liquid nitrogen $\left(\mathrm{LN}_{2}\right)$ was purchased from Air Liquide (Liege, Belgium). Chromatographic pure grade helium gas (99.9999\%) was purchased from Air Products (Vilvoorde, Belgium). The internal standard solution of the $172,3,7,8$-chloro-subsituted ${ }^{13} \mathrm{C}_{12}$ labelled PCDD/Fs congeners (EDF-4144), the calibration standard solution (EDF-4143), and the syringe (recovery) standard (EDF-4145) were purchased from Cambridge Isotope Laboratories (CIL, Andover, MS, USA). The EDF-4143, EDF-4144, and EDF-4145 concentrations of the native and labelled congeners are summarized in a previous report (Focant et al., 2001b). The ${ }^{13} \mathrm{C}_{12}$-labelled PCB internal standard spiking solution (EC-5023), as well as the ten-point calibration solution (EC-5022), was obtained from CIL. For PCDD/Fs and nonortho-PCBs, a mixture of ${ }^{13} \mathrm{C}_{6}-3,3^{\prime}, 5,5^{\prime}$-tetrachoro biphenyl (TeCB80) (Korytár, 2006), ${ }^{13} \mathrm{C}_{6}-1,2,3,4-\mathrm{TeCDD}$, and ${ }^{13} \mathrm{C}_{6}-1,2,3,4,7,8,9$ $\mathrm{HpCDF}$ was used as the recovery standard. Non-ortho-PCB recovery rates were calculated against ${ }^{13} \mathrm{C}_{6}$-TeCB-80. Recovery rates for $\mathrm{TeC}$ $\mathrm{DD} / \mathrm{F}$ and PeCDD/F were calculated against ${ }^{13} \mathrm{C}_{6}-1,2,3,4-\mathrm{TeCDD}$. Recovery rates for $\mathrm{HxCDD} / \mathrm{F}, \mathrm{HpCDD} / \mathrm{F}, \mathrm{OCDD} / \mathrm{F}$ were calculated against ${ }^{13} \mathrm{C}_{6}-1,2,3,4,7,8,9-\mathrm{HpCDF}$. Details on MS standards are available elsewhere (Pirard et al., 2003).

Because calibration solutions are based mainly on concentration levels and availability, the European Method EN-1948 standards were chosen for GC $\times$ GC-TOFMS calibration purposes. These solutions were purchased from Wellington Laboratories (Guelph, Canada) and contained the 17 native compounds and the corresponding extraction standards $\left({ }^{13} \mathrm{C}_{12}\right.$-congeners), sampling standards and syringe standards. Additional PCDD/PCDF and $\mathrm{PCB}$ calibration standards were obtained from Cambridge Isotope Laboratories (CIL, Andover, MA) and included the internal standard and the recovery standard for these compounds (EDF-4143, EDF 4144 and EDF 4145). For quantitation purposes, only the PCDD/Fs and the non-ortho substituted dioxin-like PCBs were included.

\subsection{Samples}

A hazardous waste treatment facility was investigated under suspicion of having illegally disposed of toxic materials, in contravention of the South African Environment Conservation Act (Act 73 of 1989). These materials included toxic chemical residues generated in the course of manufacturing assorted chemicals and products, including pesticides and herbicides.

The facility made use of furnaces to incinerate the waste into an inert form for disposal. After the wastes had been treated to destroy the hazardous organic compounds, sludge from settling tanks was buried on the premises in contravention of a number of laws and regulations. Information received was that the incineration process involved two stages of combustion and incineration; one at $650{ }^{\circ} \mathrm{C}$ to burn the majority of the compounds and then a second at $900{ }^{\circ} \mathrm{C}$ in an attempt to destroy residual organic compounds. The material brought to the facility for disposal thus included chemical wastes and residues. 
Samples were taken by excavating deeper holes into existing drain holes into which the sludge had been dumped. These drain holes were located in the concrete floor of a large factory building. Samples were collected in clean $250 \mathrm{~mL}$ glass sample containers with screw tops and labelled.

Sample 1 was taken from a drain hole in the floor of the factory building, lined with tiles, which was filled with oily incinerator sludge and covered with soil. The sample was taken at a depth of about $60 \mathrm{~cm}$ and consisted of a very wet, black-coloured sludge.

Sample 2 consisted of friable dry brownish yellow crusts obtained from drums that had been used for storing incinerated chemicals and chemical wastes.

Sample 3 was taken from a second drain hole in the floor, also lined with tiles, which was filled with a similar black tarry sludge material, but even higher in viscosity. The sample was covered with a layer of fresh soil placed directly on top of the sludge.

\subsection{Sample preparation}

Due to the toxic nature of the compounds, the samples were handled with care (Pereira, 2004; Davy, 2004). Ten microliters of the internal standard (EDF-4144) was spiked into the samples (Focant et al., 2001b; Eppe et al., 2004) and extracted using Soxhlet, with toluene as the solvent, followed by solvent exchange into hexane. Sample clean-up was performed using a multilayer silica column $\left(\mathrm{AgNO}_{3}, 22 \%\right.$ acid, $44 \%$ acid, basic). The final concentrated extract was then passed through a Pasteur pipette type acidic silica column prior to injection. The final sample volume was $25 \mu \mathrm{L}$. The samples were analysed in Belgium by GC-HRMS (Eppe et al., 2004; Reiner et al., 2006) and in South Africa using GC $\times$ GC-TOFMS (Focant et al., 2001b, 2004d).

\subsection{Mass spectrometric measurement}

\subsubsection{GC $\times$ GC-TOFMS}

The GC $\times$ GC-TOFMS system used in this study was a Pegasus $4 D$ (LECO Corporation, St Joseph, MI, USA). The system had an Agilent 7890 GC equipped with an Agilent 7683B autosampler, a secondary oven and a dual stage modulator. Liquid nitrogen $\left(\mathrm{LN}_{2}\right)$ was used for the cold jets and synthetic air for the hot jets. The $\mathrm{LN}_{2}$ levels were maintained using an AMI Model 186 liquid level controller.

Various GC column sets were evaluated during this study (Dorman et al., 2008). All the columns used were obtained from Restek (Bellefonte, PA, USA; column phase details can be obtained from the Restek website, http://www.Restek.com). Column combinations (primary $\left({ }^{1} \mathrm{D}\right) /$ secondary $\left({ }^{2} \mathrm{D}\right)$ ) included an Rtx-5Silms/RtxPCB, an Rtx5/Rtx-200, an Rtx-XLB/Rtx-200 ( ${ }^{1} \mathrm{D}$ columns were $30 \mathrm{~m} \times 0.25 \mathrm{~mm}$ id $\times 0.25 \mu \mathrm{m}$ df and ${ }^{2} \mathrm{D}$ columns were either $1.1 \mathrm{~m}$ or $2.0 \mathrm{~m} \times 0.18 \mathrm{~mm}$ id $\times 0.18 \mu \mathrm{m} \mathrm{df}$ ), and a $60 \mathrm{~m} \mathrm{Rtx}$-Dioxin $2 /$ Rtx-PCB. The primary and secondary columns were connected using a press-tight connector.

The system was tuned on the 414 ion from the conventional perfluorotributylamine (PFTBA) mass calibrant. This is different from the standard tuning procedure and is an attempt to improve the signal intensity at the higher mass range. All instrument functions and data processing were managed with the LECO ChromaTOF software (versions 3.34 and 4.22). Manual review of all peak identifications and integrations was performed using this software.

For this study (and measured results), the ${ }^{1} \mathrm{D}$ column used was a Restek Rtx-5Silms $(30 \mathrm{~m} \times 0.25 \mathrm{~mm}$ id $\times 0.25 \mu \mathrm{m} \mathrm{df})$ and the ${ }^{2} \mathrm{D}$ column was a Restek Rtx-PCB $(1.1 \mathrm{~m} \times 0.18 \mathrm{~mm}$ id $\times 0.18 \mu \mathrm{m} \mathrm{df})$. Two $\mu \mathrm{L}$ of the final sample extract in nonane were injected into a split/splitless injector held constant at $250^{\circ} \mathrm{C}$ in splitless mode. The primary oven temperature program was: $140^{\circ} \mathrm{C}$ for $1 \mathrm{~min}$, at $20{ }^{\circ} \mathrm{C} \mathrm{min}{ }^{-1}$ to $180{ }^{\circ} \mathrm{C}$, no hold, then at $3^{\circ} \mathrm{C} \mathrm{min}^{-1}$ to $295^{\circ} \mathrm{C}$ for $3.67 \mathrm{~min}$; total run time of $45 \mathrm{~min}$. The secondary oven was pro- gramed identical to the primary oven, but offset by $+20^{\circ} \mathrm{C}$. The MS transferline temperature was set at $270^{\circ} \mathrm{C}$. The modulator temperature offset was $30^{\circ} \mathrm{C}$. The modulation period was $5 \mathrm{~s}$ with a hot pulse time of $1.2 \mathrm{~s}$. The final optimized conditions for the MS were as follows: The ion source temperature was $250{ }^{\circ} \mathrm{C}$, the electron energy was $80 \mathrm{eV}$, and the data acquisition rate was $50 \mathrm{spec}-$ tra/s, acquisition range 100-520 u, with the detector voltage set at 1950. The mass defect setting was $-40 \mathrm{mu} / 100 \mathrm{u}$. GC conditions for the other column sets are available, on request, from the authors.

\subsubsection{GC-HRMS}

The validity of the results obtained using GC $\times$ GC-TOFMS was established first by analysing the identical samples using the GCHRMS. The PCDD/Fs and non-ortho-PCBs were measured on an Autospec Ultima high resolution mass spectrometer (Micromass, Manchester, United Kingdom) coupled to an Agilent 6890 N Series gas chromatograph equipped with an A200SE autosampler. The MS transfer line temperature was $275^{\circ} \mathrm{C}$. The column was a $50 \mathrm{~m}$ VF-5MS $(0.20 \mathrm{~mm}$ id $\times 0.33 \mu \mathrm{m} \mathrm{df})$. Helium was used as the carrier gas at a constant flow rate $\left(1.0 \mathrm{~mL} \mathrm{~min}{ }^{-1}\right)$. Five $\mu \mathrm{L}$ of the final extract in nonane were injected into a PTV injector ramped as follows: $40^{\circ} \mathrm{C}$ for $3 \mathrm{~min}$, at $720^{\circ} \mathrm{C} \mathrm{min}-1$ to $320^{\circ} \mathrm{C}$ for $4 \mathrm{~min}$, at $720^{\circ} \mathrm{C} \mathrm{min}{ }^{-1}$ to $330{ }^{\circ} \mathrm{C}$ for $43 \mathrm{~min}$. The oven temperature program was: $60^{\circ} \mathrm{C}$ for $1.5 \mathrm{~min}$, at $70^{\circ} \mathrm{C} \mathrm{m^{-1 }}$ to $200{ }^{\circ} \mathrm{C}$, at $3.2^{\circ} \mathrm{C} \mathrm{min}^{-1}$ to $235^{\circ} \mathrm{C}$ for $1.5 \mathrm{~min}$, at $3.2^{\circ} \mathrm{C} \mathrm{min}^{-1}$ to $270^{\circ} \mathrm{C}$ for $10 \mathrm{~min}$, and at $15^{\circ} \mathrm{C} \min ^{-1}$ to $310^{\circ} \mathrm{C}$ for $13 \mathrm{~min}$. The HRMS instrument was operated in SIM mode at a minimum mass resolution of 10,000. The ion source temperature was $270{ }^{\circ} \mathrm{C}$ and the EI energy was $40 \mathrm{eV}$. Additional GC and HRMS parameters, including performing conditions, followed isotope ratio checks and quantifying ions, and quality control for measurements were as described previously (Focant et al., 2001b).

Additional GC and HRMS parameters, including performing conditions, isotope ratio checks and quantifying ions and quality control for measurements were as described previously (Eppe et al., 2004).

\section{Results and discussion}

\subsection{Column combinations}

During the investigation, several different column combinations were investigated (Dorman et al., 2008). The first column set used was that developed by Hoh et al. (2007) for benchmarking purposes. This column combination worked well for the standards and gave excellent separation. However, it allows extensive wrap-around (Schoenmakers et al., 2003), and when used for the investigation of the heavily contaminated samples, in which considerable interference was present, it was found that several of the target analytes were wrapped around into regions of heavy interference. Consequently other column combinations were investigated that would be more efficient for our samples.

Another consideration was the cost of $60 \mathrm{~m}$ columns versus $30 \mathrm{~m}$ columns and this also prompted the attempt to make use of the available $30 \mathrm{~m}$ columns.

The first combination consisted of a Restek Rtx5SilMS as the ${ }^{1} \mathrm{D}$ column coupled to a shortened $(1.1 \mathrm{~m})$ Rtx-PCB column. By shortening the ${ }^{2}$ D column, relative to the length used Hoh et al., 2007, it was hoped to prevent the wrap around which had proved problematic earlier. This did indeed prove to be the case, and no wraparound was observed.

With this column set, some difficulty was experienced in assigning peak areas for the HxCDD compounds, as there was considerable overlap of $2,3,4,6,7,8-\mathrm{HxCDF}, 1,2,3,4,7,8-\mathrm{HxCDD}$ and 
1,2,3,6,7,8-HxCDD (Fig. 1). This resulted in overlap in the second dimension of separation. An alternative ${ }^{1} \mathrm{D}$ and ${ }^{2} \mathrm{D}$ column set combination was investigated for further analysis and method validation of $\mathrm{PCDD} / \mathrm{Fs}$. The choice of ${ }^{2} \mathrm{D}$ columns is somewhat restricted by the high temperature demands of the analysis. A combination of a ${ }^{1} \mathrm{D}$ Rtx-5 and ${ }^{2} \mathrm{D}$ Rtx-200 column was selected. With this combination the two HxCDFs $(1,2,3,4,7,8-\mathrm{HxCDF}$ and $1,2,3,6,7,8-\mathrm{HxCDF})$ and the two HxCDDs (1,2,3,4,7,8-HxCDD and $1,2,3,6,7,8-\mathrm{HxCDD})$ were still inclined to overlap in the second chromatographic dimension, but the three problem compounds in the separation were more clearly resolved; namely $2,3,4,6,7,8$ HxCDF, 1,2,3,4,7,8-HxCDD and 1,2,3,6,7,8-HxCDD.

Since the improved separation was clearly achieved using the Rtx-200 in the ${ }^{2} \mathrm{D}$, another column combination was considered. A Rxi-XLB gave improved ${ }^{1} \mathrm{D}$ separation, not only for the hexa-compounds, but also for the octa-compounds and this led to improved quantitation of the $1,2,3,7,8,9-\mathrm{HxCDF}, 1,2,3,4,7,8-\mathrm{HxCDD}$ and $1,2,3,6,7,8-H x C D D ;$ the method development using the Rxi-XLB/ Rtx-200 column combination is detailed in a further paper submitted for publication (de Vos et al., submitted for publication).

The wrap-around, which had been a problem with the analysis using a ${ }^{2}$ D Rtx-PCB column, did not occur using a $2 \mathrm{~m}^{2} \mathrm{D}$ Rtx-200 column. Depending on the analytical separation required, Rtx-5, Rtx5Silms or Rxi-XLB (or equivalent) phases can be used for the ${ }^{1} \mathrm{D}$ separation; it just depends on the separation required for all the PCDD and PCDF congeners. To achieve the ${ }^{1} \mathrm{D}$ separation, the column temperature conditions for the Rtx-XLB/Rtx-200 separation were varied for optimization of the method (de Vos et al., submitted for publication).
The analytical data for the samples was collected using the Rtx5silms/Rtx-PCB column set and the quantitative results obtained are discussed in Section 3.3.

\subsection{Qualitative investigation of sample compounds}

Preliminary analysis of the toxic waste samples was performed by GC-TOFMS and indicated that the incineration process had not been sufficient to completely destroy the organic compounds present. This raised a concern that many more toxic compounds were not being detected. This indicated that the disposal process was being improperly carried out at too low temperatures, potentially leading to the creation of even more toxic materials, such as PCDDs and PCDFs.

The advantage of the GC $\times$ GC-TOFMS approach compared with the GC-HRMS method is that it is possible to locate and identify numerous additional compounds in a single run with similar selectivity that is achieved with high resolution single ion monitoring (HR-SIM). The use of a scanning system with SIM requires a target list so that the necessary SIM parameters can be applied to the analysis. Only those compounds meeting the conditions of the SIM experiment will be located, and identification rests on retention time comparison and the relative ratios of the selected ions. In a complex sample such as this, it is possible that PCB congeners may overlap (209 congeners). Using GC $\times$ GC-TOFMS it is possible to locate and identify all the compounds of the sample in one run, using full range mass spectra to confirm compound identity.

In addition to PCDDs and PCDFs, the three samples analyzed contained numerous other environmental pollutants. Among these

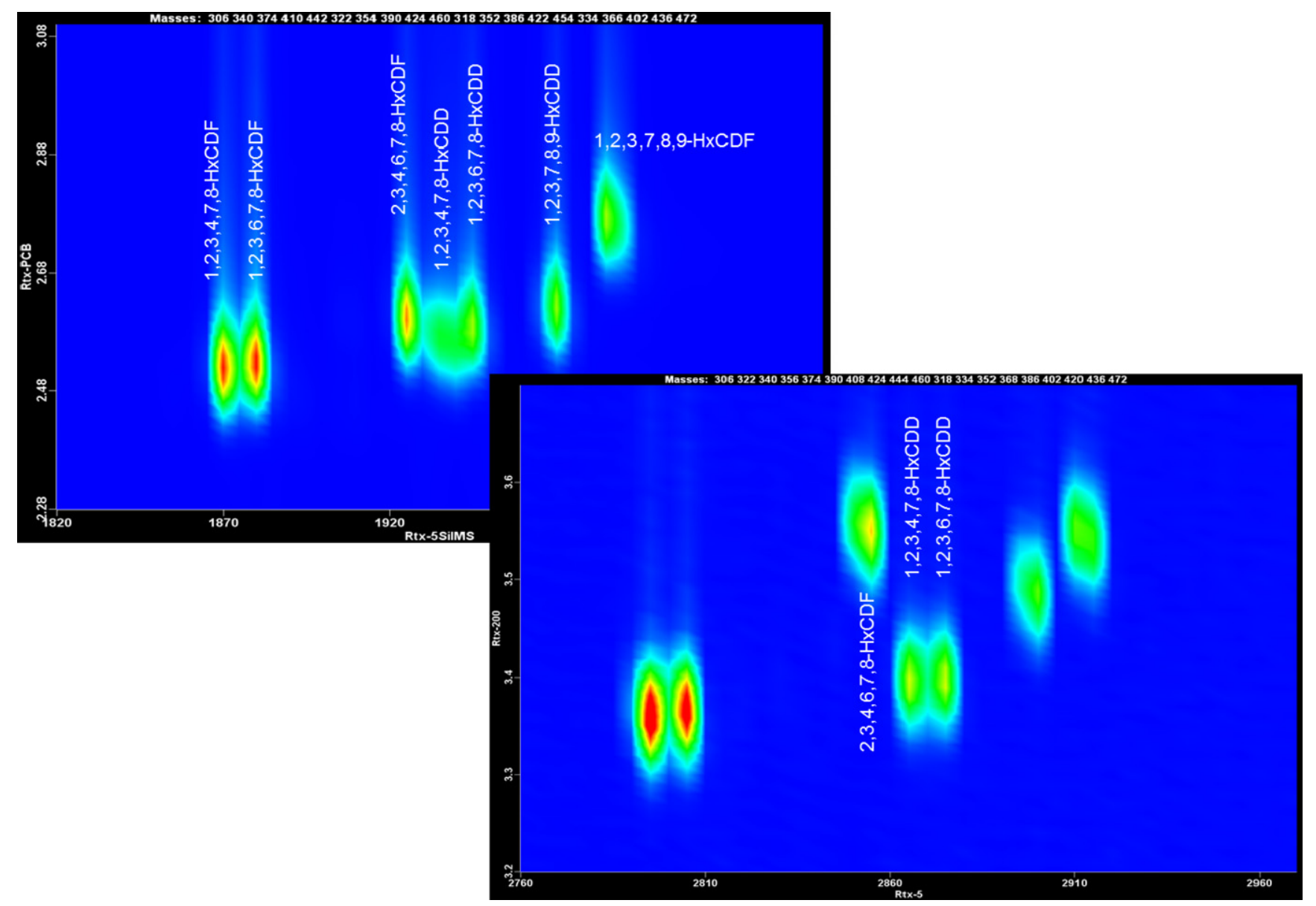

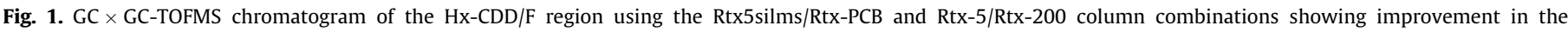
separation for the $1,2,3,4,7,8$ - and $1,2,3,6,7,8-H x C D D s$.

Please cite this article in press as: de Vos, J., et al. Comprehensive two-dimensional gas chromatography time of flight mass spectrometry (GC $\times$ GC-TOFMS) for environmental forensic investigations in developing countries. Chemosphere (2011), doi:10.1016/j.chemosphere.2010.12.039 


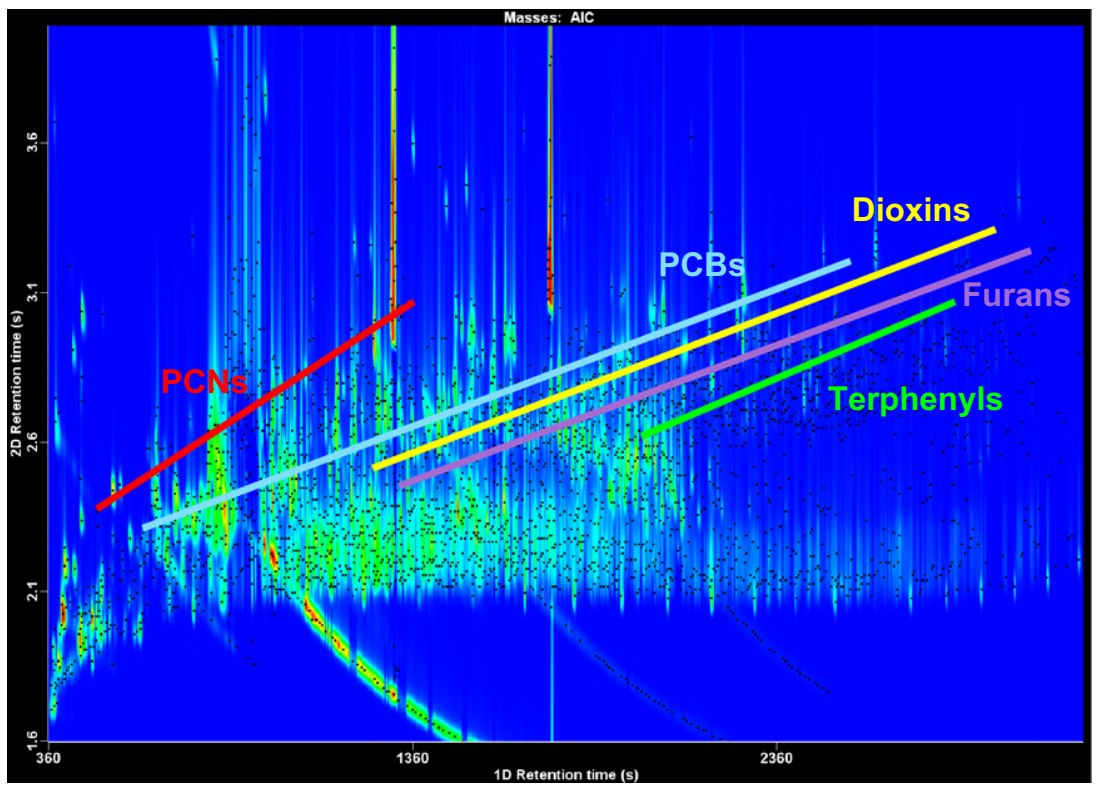

Fig. 2. Analytical ion chromatogram contour plot showing selected priority pollutant classes.

were polychloro biphenyls (PCBs), polycyclic aromatic hydrocarbons (PAHs), polychloro naphthalenes (PCNs), terphenyls, chlorinated terphenyls, chlorinated furans and chlorinated pyrenes, as well as several other chlorinated and brominated aromatics. As an example of what is possible with this technique, a number of figures will demonstrate the ease with which compound classes can be located by plotting chromatograms displaying selected ions that are characteristic of the compound class.

A plot of the Analytical Ion Chromatogram (AIC) for sample 3 provides an overall picture of the sample, including the important pollutant compound classes. The AIC plot is similar to the Total Ion Chromatogram (TIC), but without column bleed ion interference; it serves as a type of filter. This ChromaTOF software feature is shown in Fig. 2.

Once samples have been analysed and the data processed to locate and identify sample compounds, it is possible to use features of the software to facilitate the detection of hazardous compounds. These features are known as Classification and Scripting. Classifications can be used to define areas of the two dimensional chromatogram where compound classes occur, and Scripting provides the facility to use VBScript programming to establish rules for filtering spectral data to locate compounds with defined spectral properties (LECO Corporation, 2008; Pierce et al., 2008; Hilton et al., 2010). This is particularly useful in searching for compounds that contain either chlorine or bromine atoms. The isotope ratios found in the mass spectrum of a compound containing these atoms are characteristic and easily located using a Script written to search for these defined isotope ratios. Many highly hazardous compounds are chlorinated and the ability to locate these quickly and efficiently enhances sample evaluation. Sample 3 contains many compounds (over 7360 were located at a $\mathrm{S} / \mathrm{N}$ of 100 ) and it becomes both tedious and difficult to manually sort for compound classes and structural features.

Fig. 3a shows the same data as presented in Fig. 2, but in the form of an Apex Plot generated using Microsoft Excel. Using this simplified presentation of the data, only the position of the different compounds is shown and no intensity data is presented.

Fig. $3 \mathrm{~b}$ shows the results of the automated spectral search for chlorinated compounds in the sample using the Script as described (the script used was "AllChlorine", obtained as part of the ChromaTOF software package provided by LECO Corporation). Chlorinated compounds have been located using mass spectral filtering of the data, searching for multiple chlorine isotope ratio patterns. As is evident, the majority of the chlorinated compounds lie in a restricted area across the chromatogram, and this approach allows a fast, convenient screen to determine the extent of chlorination in the sample (extremely high in this case). The number of located compounds is greatly reduced, from 7368 to only 603, permitting many potential priority pollutants to be located.

By selecting appropriate ions it is possible to highlight some of the individual compound classes present in the sample, as is shown in the Apex Plot chromatogram in Fig. 4. Detailed information can be obtained in this manner about complex samples, and the samples are easily screened for numerous pollutant classes. In addition, the data can be presented in a simple format which is easy to visualize, providing an overview of the information contained in the sample. With ${ }^{1} \mathrm{D}-\mathrm{GC}$, complex environmental samples contain too much interference for detailed analysis of this type.

PCNs are characterized by major ions at $m / z$ 162, 196, 230, 266, $300,334,368$ and 404 . These compounds are represented as bright red squares in Fig. 4. Mono- through octa-PCNs are found in the sample. Similarly, by plotting the major characteristic ions for e.g., chlorinated terphenyls $(m / z 264,298,332,368,402,436$, 470 and 506), these compounds can be located in the sample (green triangles). Again, mono- through octa-chlorinated terphenyls are found. PCBs $(m / z 188,222,256,292,326,360,394,428$, 464 , and 498 - blue diamonds), PCDDs ( $m / z 218,252,286,322$, $356,390,424$, and 460 - yellow circles) and PCDFs $(m / z 202$, $236,270,306,240,374,408$ and 444 - purple squares) can also be located in the chromatogram.

The acquisition of full range mass spectra for all the compounds of the sample means that in one run the sample can be examined for all the pollutants of interest, providing an ideal screen which is quick and efficient. No other technique provides the same degree of flexibility. GC $\times$ GC provides the selectivity needed and TOFMS gives levels of detection which can meet the requirements of regulatory bodies.

The selectivity and sensitivity enhancements of GC $\times$ GC-TOFMS, coupled to the de-convolution algorithm contained in the ChromaTOF software package, provide clean, library searchable 

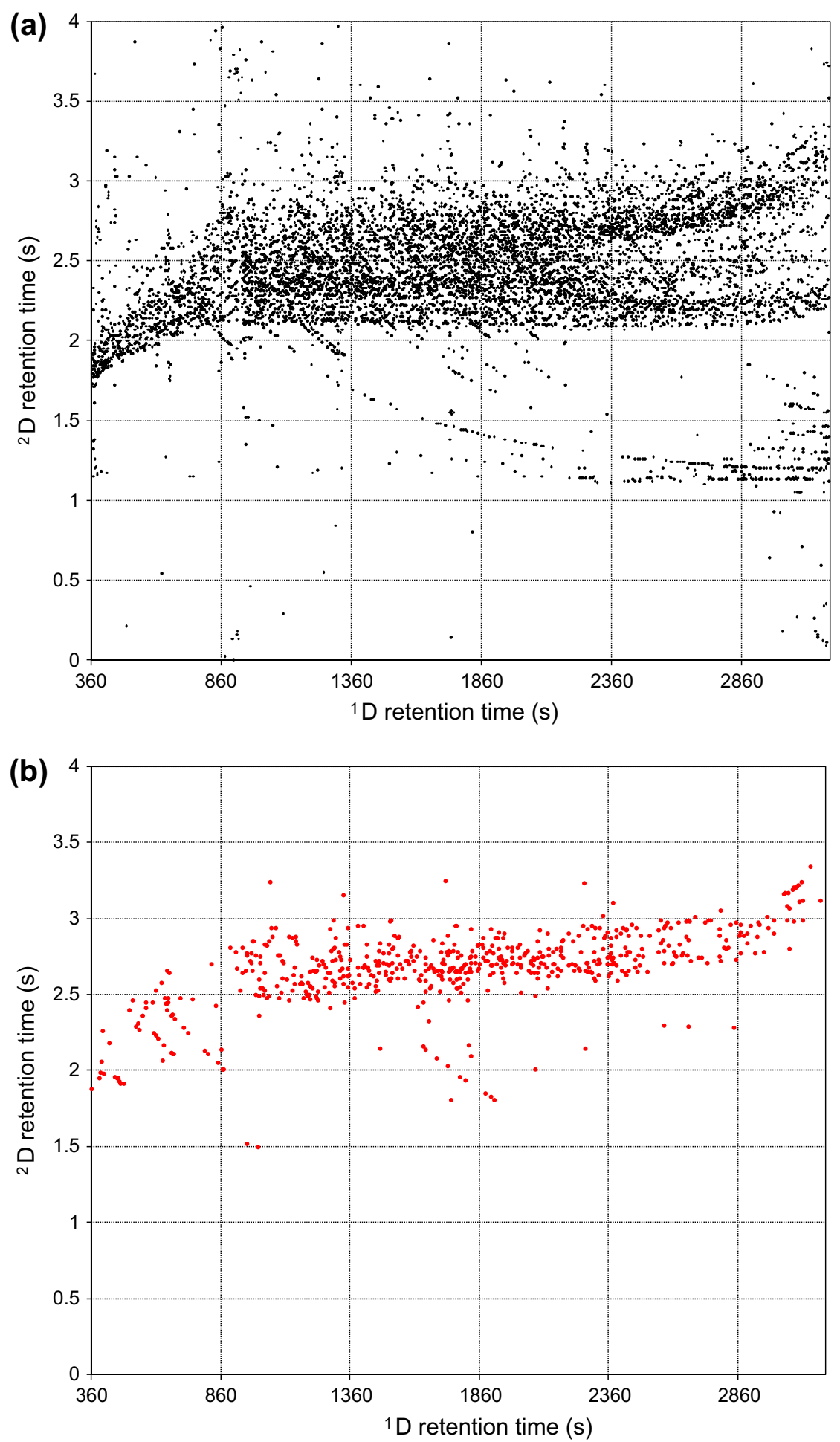

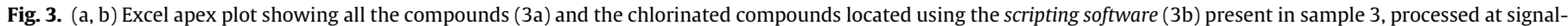
to-noise $(\mathrm{S} / \mathrm{N})$ of 100 .

spectra even with closely eluting compounds. For example, the PAH compounds at retention times $1080,2.630 \mathrm{~s}$ and 1080 , $2.810 \mathrm{~s}$ are separated by only $180 \mathrm{~ms}$, yet the mass spectra produced for these compounds are clean and contain little spectral interference. The quality of the spectra is excellent, emphasizing the ability of the software to produce clean spectra, which can be accurately matched to library spectra, even for closely eluting compounds (chloronaphthalenes and PAHs).

\subsection{Quantitative measurement of PCDDs, PCDFs and PCBs}

Prior to sample quantitation, calibration curves were generated for the 17 PCDDs and PCDFs required by EPA method 1613. This required the calculation of a relative response factor (RRF) according to the formula: $\mathrm{RRF}=$ Area ${ }^{12} \mathrm{C} /$ Area ${ }^{13} \mathrm{C} \times\left[{ }^{13} \mathrm{C}\right] /$ $[12 \mathrm{C}]$, where $\left[{ }^{12} \mathrm{C}\right]$ and $\left[{ }^{13} \mathrm{C}\right]$ are the concentrations of native and labelled material. The value is then used to calculate the 
concentration of unknown material in the sample to be quantified, after first adding a known amount of the labelled component. The PCDD/Fs used for quantification (as ion ratios) were as follows: 306/318, 340/352, 374/386, 408/420, 444/456 for the PCDFs and PCDDs; 322/334, 356/368, 390/402, 424/436, $460 / 472$ for the PCDDs. During the calculation a correction for a

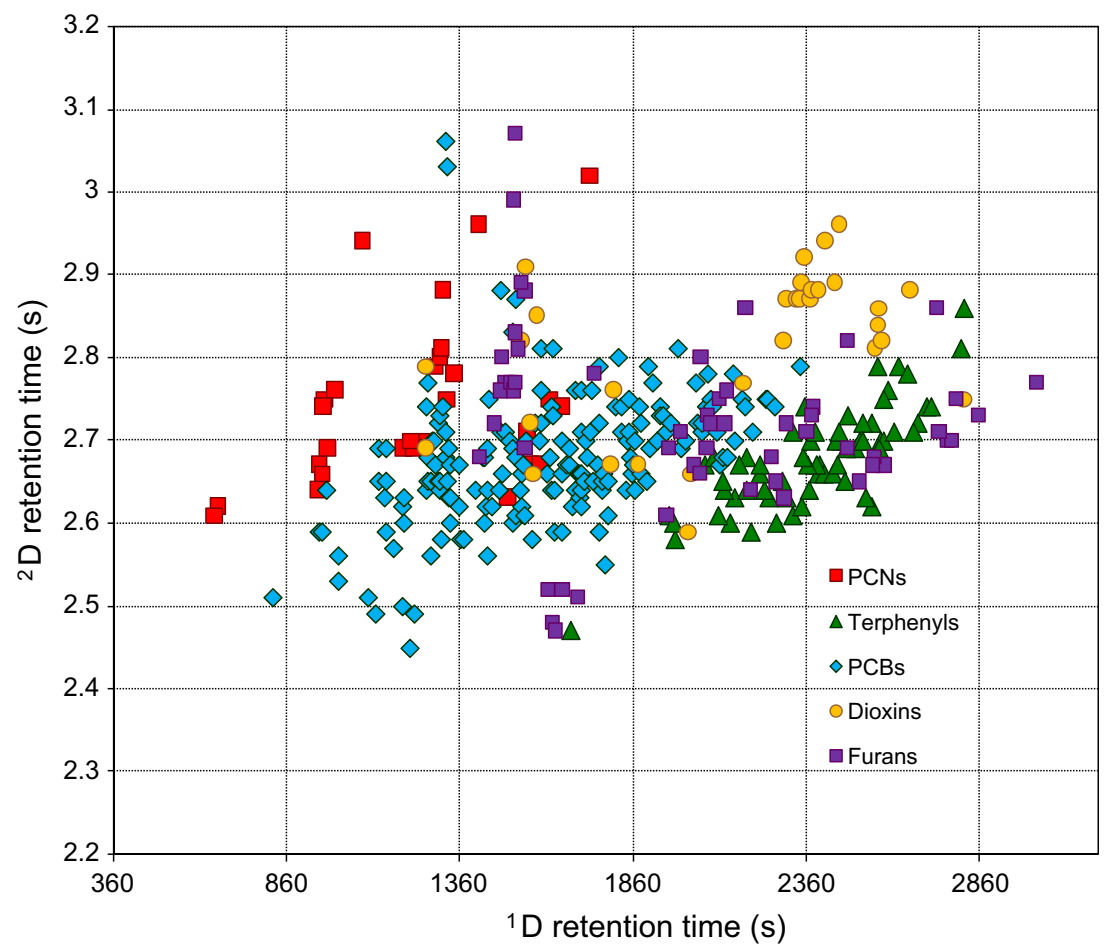

Fig. 4. Apex plot of selected chlorinated extracted ions for sample 3.

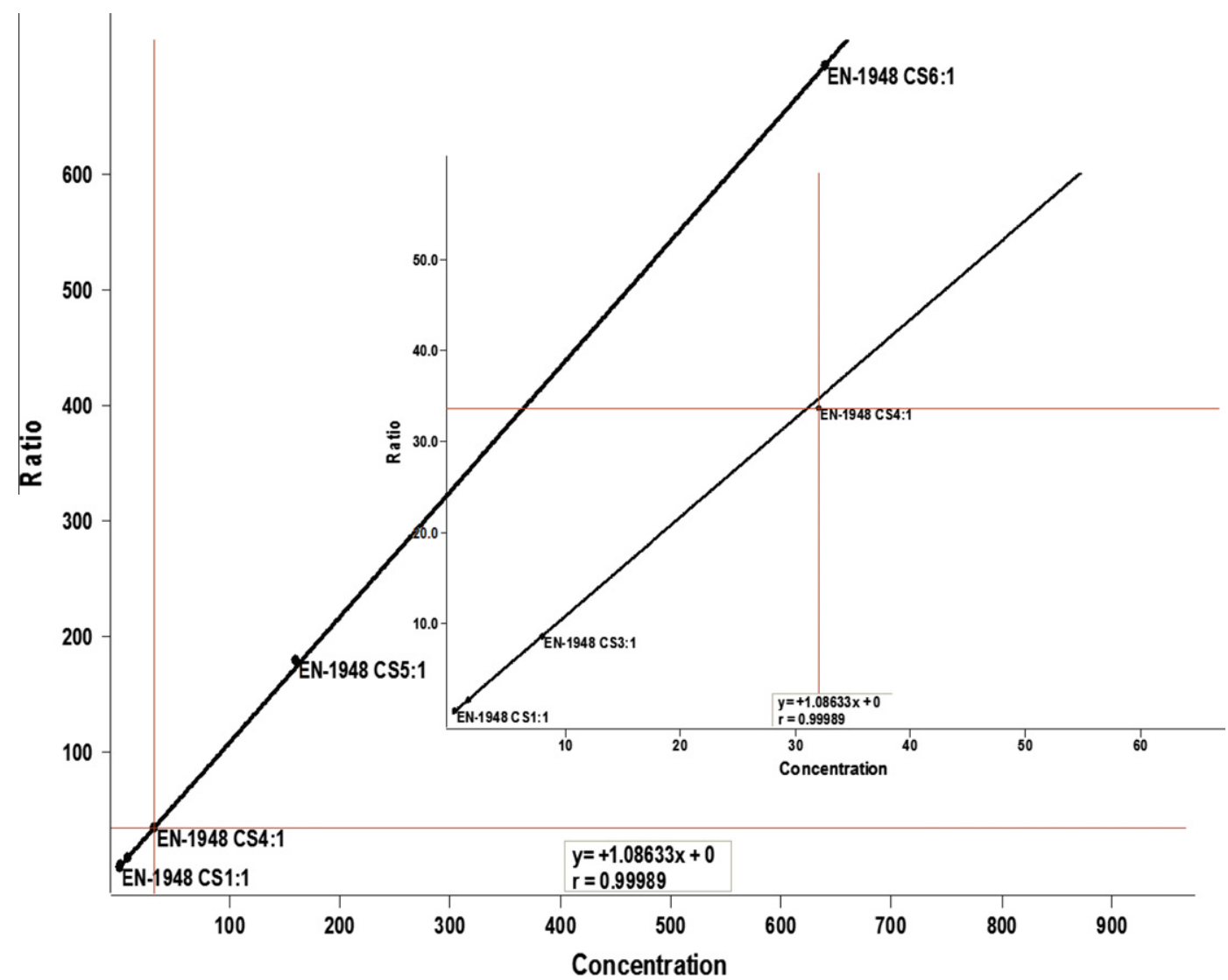

Fig. 5. Calibration curve (and expanded calibration curve insert) for 1,2,3,7,8-PeCDF. 
Table 1

Quantitative results obtained for the 17 PCDD/Fs and dioxin-like non-ortho PCBs.

\begin{tabular}{|c|c|c|c|c|c|c|c|c|c|c|c|c|}
\hline & \multicolumn{4}{|l|}{ Soil 1} & \multicolumn{4}{|l|}{ Soil 2} & \multicolumn{4}{|l|}{ Soil 3} \\
\hline & $\begin{array}{l}\mathrm{GC} \times \mathrm{GC} \\
\text { TOFMS } \\
\left(\mathrm{ng} \mathrm{kg}^{-1}\right)\end{array}$ & $\begin{array}{l}\text { GC HRMS } \\
\left(\mathrm{ng} \mathrm{kg}^{-1}\right)\end{array}$ & $\begin{array}{l}\text { GC } \times \text { GC } \\
\text { TOFMS } \\
(\mathrm{ng} \text { WHO } \\
\left.\text { TEQ kg }{ }^{-1}\right)\end{array}$ & 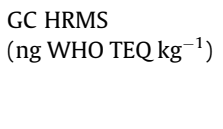 & $\begin{array}{l}\mathrm{GC} \times \mathrm{GC} \\
\text { TOFMS } \\
\left(\mathrm{ng} \mathrm{kg}^{-1}\right)\end{array}$ & $\begin{array}{l}\text { GC HRMS } \\
\left(\mathrm{ng} \mathrm{kg}^{-1}\right)\end{array}$ & 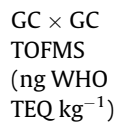 & $\begin{array}{l}\text { GC HRMS } \\
(\text { (ng WHO } \\
\text { TEQ kg-1) }\end{array}$ & $\begin{array}{l}\mathrm{GC} \times \mathrm{GC} \text { TOFMS } \\
\left(\mathrm{ng} \mathrm{kg}^{-1}\right)\end{array}$ & $\begin{array}{l}\text { GC HRMS } \\
\left(\mathrm{ng} \mathrm{kg}^{-1}\right)\end{array}$ & $\begin{array}{l}\mathrm{GC} \times \mathrm{GC} \\
\text { TOFMS } \\
(\mathrm{ng} \text { WHO } \\
\left.\mathrm{TEQ} \mathrm{kg}^{-1}\right)\end{array}$ & $\begin{array}{l}\text { GC HRMS } \\
(\text { ng WHO } \\
\text { TEQ kg }^{-1} \text { ) }\end{array}$ \\
\hline 2,3,7,8-TeCDD & $\mathrm{ND}^{\mathrm{a}}$ & ND & $\mathrm{ND}^{\mathrm{a}}$ & ND & $\mathrm{ND}^{\mathrm{a}}$ & ND & $\mathrm{ND}^{\mathrm{a}}$ & ND & 590 & 510 & 590 & 510 \\
\hline $1,2,3,7,8-\mathrm{PeCDD}$ & 18 & 2.7 & 18 & 2.7 & 7.5 & 2.8 & 7.5 & 2.8 & 940 & 770 & 940 & 770 \\
\hline 1,2,3,4,7,8-HxCDD & ND & 5.5 & ND & 0.5 & ND & 2.1 & ND & 0.2 & 430 & 400 & 42 & 40 \\
\hline 1,2,3,6,7,8-HxCDD & ND & 6.8 & ND & 0.7 & 4.4 & 4.1 & 0.4 & 0.4 & 710 & 700 & 71 & 70 \\
\hline $1,2,3,7,8,9-\mathrm{HxCDD}$ & 23 & 5.6 & 2.3 & 0.6 & ND & ND & ND & ND & 440 & 440 & 44 & 44 \\
\hline $1,2,3,4,6,7,8-\mathrm{HpCDD}$ & 98 & 52 & 0.9 & 0.5 & 7.6 & 8.9 & 0.1 & 0.1 & 2500 & 2300 & 25 & 23 \\
\hline OCDD & 180 & 110 & 0.1 & 0.1 & 13 & 14 & 0.05 & 0.05 & 2800 & 2200 & 0.8 & 0.7 \\
\hline 2,3,7,8-TeCDF & 130 & 120 & 13 & 12 & 71 & 69 & 7.1 & 6.9 & 10800 & 8800 & 1080 & 880 \\
\hline $1,2,3,7,8-\mathrm{PeCDF}$ & 41 & 30 & 1.2 & 0.9 & 14 & 18 & 0.4 & 0.5 & 4450 & 3800 & 130 & 110 \\
\hline 2,3,4,7,8-PeCDF & 60 & 69 & 18 & 21 & 64 & 47 & 19 & 14 & 5100 & 4400 & 1500 & 1320 \\
\hline $1,2,3,4,7,8-\mathrm{HxCDF}$ & 36 & 48 & 3.6 & 4.8 & 18 & 18 & 1.8 & 1.8 & 3100 & 3200 & 300 & 330 \\
\hline $1,2,3,6,7,8-\mathrm{HxCDF}$ & 43 & 43 & 4.3 & 4.3 & 15 & 15 & 1.5 & 1.5 & 2600 & 2900 & 260 & 300 \\
\hline $2,3,4,6,7,8-\mathrm{HxCDF}$ & 54 & 53 & 5.4 & 5.3 & 13 & 15 & 1.3 & 1.5 & 2900 & 2900 & 290 & 290 \\
\hline $1,2,3,7,8,9-\mathrm{HxCDF}$ & 23 & 20 & 2.3 & 2.0 & 8.9 & 6.4 & 0.9 & 0.6 & 840 & 850 & 80 & 85 \\
\hline $1,2,3,4,6,7,8-\mathrm{HpCDF}$ & 250 & 240 & 2.5 & 2.4 & 39.46 & 29.17 & 0.4 & 0.3 & 7400 & 7550 & 74 & 75 \\
\hline $1,2,3,4,7,8,9-\mathrm{HpCDF}$ & 160 & 90 & 1.6 & 0.4 & 12 & 8.8 & 0.1 & 0.1 & 2300 & 1800 & 23 & 18 \\
\hline $\mathrm{OCDF}$ & 290 & 300 & 0.1 & 0.1 & 84 & 79 & 0.02 & 0.02 & 5200 & 4900 & 1.6 & 1.5 \\
\hline TOTAL PCDD/Fs & & & 80 & 60 & & & 40 & 30 & & & 5500 & 5000 \\
\hline РСВ 81 & 65,300 & 100300 & 19 & 30 & 46000 & 62000 & 14 & 19 & 18400 & 80500 & 5.5 & 24 \\
\hline РСВ 77 & 3000 & 1900 & 0.3 & 0.1 & 1300 & 950 & 0.1 & 0.1 & 2700 & 2600 & 0.3 & 0.3 \\
\hline РCB 126 & 3204 & 240 & 32 & 24 & 300 & 280 & 32 & 28 & 9000 & 9000 & 890 & 890 \\
\hline PCB 169 & $\mathrm{ND}^{\mathrm{b}}$ & ND & $\mathrm{ND}^{\mathrm{b}}$ & ND & 7.1 & 6.6 & 0.2 & 0.2 & 830 & 390 & 25 & 12 \\
\hline TOTAL Dioxin like PCBs & & & 50 & 50 & & & 50 & 50 & & & 930 & 930 \\
\hline TOTAL TEQs & & & 130 & 110 & & & 90 & 80 & & & 6400 & 5800 \\
\hline \% Difference & & & $15 \%$ & & & & $11 \%$ & & & & $9 \%$ & \\
\hline
\end{tabular}

a Detection limit for $2,3,7,8-\mathrm{TeCDD}=0.43 \mathrm{ng} \mathrm{kg}^{-1}$, assuming $70 \%$ extraction efficiency.

Detection limits not determined for PCBs. 
blank (BC) can be implemented: $\left[{ }^{12} \mathrm{C}\right]=\left(\left(\right.\right.$ Area ${ }^{12} \mathrm{C} /$ Area ${ }^{13} \mathrm{C} \times\left[{ }^{13} \mathrm{C}\right] /$ RRF $\left.\left.)-\mathrm{BC}\right)\right) \times(1 /$ sample weight $)$.

Fig. 5 gives an example of a calibration curve obtained for $1,2,3,7,8$-PeCDF with a correlation co-efficient of 0.99989 . The linearity obtained in the calibration curves is excellent and even the low level compounds are easily detected (standard EN-1948 CS1 has a $1,2,3,7,8-P e C D F$ concentration of $400 \mathrm{fg} \mu \mathrm{L}^{-1}$, and EN-1948 CS2 is $1.6 \mathrm{pg} \mu \mathrm{L}^{-1}$ ).

The signal to noise ratio was calculated as 9.45 using the 322 ion for $200 \mathrm{fg} \mu \mathrm{L}^{-1}$ of 2,3,7,8-TeCDD. The increased sensitivity of the GC $\times$ GC method, when compared to other low resolution ${ }^{1} \mathrm{D}$ GC-MS methods, arises from the focusing effect obtained from the modulator (Focant et al., 2004c; Reiner et al., 2006). The correlation co-efficient achieved was excellent and ranged from 0.9999 for the 2,3,7,8-TeCDD to 0.9996 for OCDD over the entire calibration. The sensitivity and accuracy (de Vos et al., submitted for publication) for all of the compounds in the standard mixture is sufficient to satisfy the requirements of EPA method 1613 (Table 1).

Admittedly, standards provide an idealized case in which no interference is present in the sample, but still the ease with which the low levels are detected and quantified shows that the method can achieve the very low levels needed for persistent organic pollutant analysis. Accurate quantitation should be possible at $500 \mathrm{fg}$ on column, with limits of detection lower than this (de Vos et al., submitted for publication; EPA Method 1613, 1994).

An evaluation of the interference on the quantitation masses can be obtained by comparing the expected isotope ratio values for the native and labelled ions with the measured value [a 20\% deviation is allowed (EPA Method 1613, 1994)]. As an example, to quantify the 2,3,7,8-TeCDD, the $m / z 322$ (native) and $m / z 334$ (label) ions are used. By measuring the ratio between $\mathrm{m} / \mathrm{z} 320 /$ 322 and 332/334 and comparing these ratios to the calculated values, we can determine if interference is present on these ions that might impede accurate quantitation. This is done automatically through the software. Even at the lowest level standard (500 fg on column), the ion ratio check was passed.

Having generated results for the three samples, the measured values (TEF, TEQ) obtained using both GC $\times$ GC-TOFMS and GCHRMS for the 17 PCDD/Fs, as required by EPA 1613, are shown in Table 1 (van den Berg et al., 2006).

In nearly all cases the values obtained from the GC $\times$ GC-TOFMS are in good agreement with those obtained using GC-HRMS. In general the values using the new technology, (GC $\times$ GC-TOFMS), are slightly higher than those using the traditional methodology (GC-HRMS). There are a number of possible reasons for this: In the case of the GC $\times$ GC-TOFMS results, no background subtraction was performed. This may slightly influence the results even though blank runs were made between each standard and sample run. There was also no evidence of carry-over or any build up of interference between runs.

The sample complexity could lead to interference on a quantitation mass, and produce artificially high values for the compound being determined. This is a possibility when assessing the consistently higher value obtained for PCB 81 (possible interference from PCB 87) (Table 1). The low TEF value obtained for PCB 81 (0.0003, van den Berg et al., 2006) means that the contribution to the overall sample TEQ value is actually negligible.

This method was intended to act primarily as a screening method, and consequently it was kept as simple as possible. As there was no evidence of background problems, no correction was deemed necessary for the purposes of this study.

Table 1 provides a better evaluation of the differences between new and traditional technology. In this case, the toxic equivalency factors are used to determine an overall total toxic equivalence for the samples (excluding the mono-ortho indicator PCBs). As indi- cated in Table 1 , the values for each sample are comparable between methods, although the GC $\times$ GC-TOFMS results are slightly higher. For a screening method this is not undesirable, as this guarantees that samples sent for further investigation will be biased so that low positives will not be excluded. The congener pattern of the PCDDs as calculated for sample 3 is atypical and does not resemble naturally occurring PCDD values. However, as this sample arises from incomplete combustion in a furnace operating at inadequate temperatures, no conclusions can be drawn.

\section{Conclusions}

The work described was intended as an investigative tool which could be reliably implemented to evaluate samples containing significant levels of compounds detrimental to human and animal health. It has been shown that the GC $\times$ GC-TOFMS approach provides a quick convenient screen for numerous pollutant classes which may be present in samples arising from toxic waste disposal where incineration practices are badly designed or poorly executed. This can then be used as a possible test for determination of incineration efficiency and safety. Software features present in the ChromaTOF software can be used to enhance and speed up the evaluation process.

In addition, the technique can be used to quantify PCDDs and PCDFs. The technique is also more affordable and robust for developing countries intending to analyse PCDDs and PCDFs. Positive samples could then be subjected to further investigation using GC-HRMS. The close correlation between values obtained using the GC $\times$ GC-TOFMS approach and the established GC-HRMS method confirms the validity of this technique to quantify these compounds at levels required by regulatory bodies. Although the values with the GC $\times$ GC-TOFMS method are consistently higher than those obtained with the established technique, the differences are certainly within permissible levels, considering that the analyses were performed in different laboratories and this was the first attempt to analyse such complex samples for PCDDs and PCDFs in South Africa.

The methods described above are fast, convenient and produce accurate results. Indeed the level of accuracy is excellent when compared to results using accepted technology, and it would not be surprising if the methodology using the low resolution system finds acceptance for quantitative work as well, in addition to being a valuable tool for overall sample assessment. The sensitivity needed is provided by the focusing effect of the modulator, and the selectivity gain from the two-dimensional chromatographic separation effectively compensates for that lost by the lower resolution mass spectrometer.

\section{Appendix A. Supplementary data}

Supplementary data associated with this article can be found, in the online version, at doi:10.1016/j.chemosphere.2010.12.039.

\section{References}

Batterman, S., Chernyak, S., Gouden, Y., Hayes, J., Robins, T., Chetty, S., 2009. PCBs in air, soil and milk in industrialized and urban areas of KwaZulu-Natal, South Africa. Environmental Pollution 157 (2), 654-663.

Birnbaum, L.S., De Vito, M.J., 1995. Use of toxic equivalency factors for risk assessment for dioxins and related compounds. Toxicology 105, 391-401.

European Standard Method BS EN 1948-1:2006. Stationary source emissions. Determination of the mass concentration of PCDDs/PCDFs and dioxin-like PCBs. Extraction and clean-up of PCDDs/PCDFs. BSI Group, London, UK.

Commission Regulation (EC) No. 1881, 2006. Setting Maximum Levels for certain Contaminants in Foodstuffs, Official Journal of the European Union. L 364, 5-24.

Davy, C.W., 2004. Legislation with respect to dioxins in the workplace. Environment International 30 (2), 219-233.

De Vos, J., Gorst-Allman, P., Rohwer, E., submitted for publication. An evaluation of the analysis of polychlorinated dibenzo-p-dioxins and polychlorinated 
dibenzofurans by comprehensive gas chromatography time of flight mass spectrometry. Journal of Chromatography A.

Dimandja, J.-M.D., Clouden, G.C., Colón, I., Focant, J.-F., Cabey, W.V., Parry, R.C., 2003. Standardized test mixture for the characterization of comprehensive twodimensional gas chromatography columns: the Phillips mix. Journal of Chromatography A 1019, 261-272.

Dorman, F.L., Overton, E.B., Whiting, J.J., Cochran, J.W., Gardea-Torresdey, J., 2008. Gas chromatography. Analytical Chemistry 80 (12), 4487-4497.

EPA Method 1613: 1994. Tetra through Octa-Chlorinated Dioxins and Furans by Isotopic Dilution HRGC/HRMS. Us Environmental Protection Agency, Washington, DC, USA.

Eppe, G., Focant, J.-F., Pirard, C., De Pauw, E., 2004. PTV-LV-GC/MS/MS as screening and complementary method to HRMS for the monitoring of dioxin levels in food and feed. Talanta 63 (5), 1135-1146

Focant, J.-F., Eppe, G., De Pauwa, E., 2001a. Optimisation and use of tandem-in-time mass spectrometry in comparison with immunoassay and HRGC/HRMS for PCDD/F screening. Chemosphere 43, 417-424.

Focant, J.-F., Eppe, G., Pirard, C., De Pauw, E., 2001b. Fast clean-up for polychlorinated dibenzo-p-dioxins, dibenzofurans and coplanar polychlorinated biphenyls analysis of high-fat-content biological samples. Journal of Chromatography A 925, 207-221.

Focant, J.-F., Sjödin, A., Patterson Jr., D.G., 2003. Qualitative evaluation of thermal desorption-programmable temperature vaporization-comprehensive twodimensional gas chromatography-time-of-flight mass spectrometry for the analysis of selected halogenated contaminants. Journal of Chromatography A 1019, 143-156.

Focant, J.-F., Cochran, J.W., Dimandja, J.-M.D., De Pauw, E., Sjödin, A., Turner, W.E., Patterson Jr., D.G., 2004a. High-throughput analysis of human serum for selected polychlorinated biphenyls (PCBs) by gas chromatography-isotope dilution time-of-flight mass spectrometry (GC-IDTOFMS). The Analyst 129, 331-336.

Focant, J.-F., Pirard, C., Eppe, G., De Pauw, E., 2004b. Recent advances in mass spectrometric measurement of dioxins. Journal of Chromatography A 1067, $265-275$.

Focant, J.F., Reiner, E.J., Macpherson, K., Kolic, T., Sjödin, A., Patterson Jr., D.G., Reese, S.L., Dorman, F.L., Cochran, J.W., 2004c. Measurement of PCDDs, PCDFs, and non-ortho-PCBs by comprehensive two-dimensional gas chromatographyisotope dilution time-of-flight mass spectrometry (GC $\times$ GC-IDTOFMS). Talanta 63, 1231-1240.

Focant, J.-F., Sjödin, A., Patterson Jr, D.G., 2004d. Improved separation of the 209 polychlorinated biphenyl congeners using comprehensive two-dimensional gas chromatography-time-of-flight mass spectrometry. Journal of Chromatography A $1040,227-238$.

Focant, J.-F., Sjödin, A.S., Turner, W.E., Patterson Jr., D.G., 2004e. Measurement of selected polybrominated diphenyl ethers, polybrominated and polychlorinated biphenyls, and organochlorine pesticides in human serum and milk using comprehensive two-dimensional gas chromatography isotope dilution time-offlight mass spectrometry. Analytical Chemistry 76 (21), 6313-6320.

Hilton, D.C., Jones, R.S., Sjödin, A.S., 2010. A method for rapid, non-targeted screening for environmental contaminants in household dust. Journal of Chromatography A 1217, 6851-6856.

Hoh, E., Mastovska, K., Lehotay, S.J., 2007. Optimization of separation and detection for comprehensive two-dimensional gas chromatography-time-of-flight mass spectrometry analysis of polychlorinated dibenzo- $p$-dioxins and dibenzofurans. Journal of Chromatography A 1145, 210-221.

Korytár, P., 2006. Comprehensive Two-Dimensional Gas Chromatography with Selective Detection for the Trace Analysis of Organohalogenated Contaminants. The Netherlands.

LECO Corporation, 2008. Using Scripting in ChromaTOFTM. Leco Separation Sciences Applications Support Guides. St. Joseph, Mi.

Pereira, de Souza M., 2004. Polychlorinated dibenzo-p-dioxins (PCDD), dibenzofurans (PCDF) and polychlorinated biphenyls (PCB): main sources, environmental behaviour and risk to man and biota. Quimica Nova 27 (6), 934943.

Pierce, K.M., Hoggard, J.C., Mohler, R.E., Synovec, R.E., 2008. Recent advancements in comprehensive two-dimensional separations with chemometrics. Journal of Chromatography A 1184 (1-2), 341-352.

Pirard, C., De Pauw, E., Focant, J.-F., 2003. New strategy for comprehensive analysis of polybrominated diphenyl ethers, polychlorinated dibenzo-p-dioxins, polychlorinated dibenzofurans and polychlorinated biphenyls by gas chromatography coupled with mass spectrometry. Journal of Chromatography A 998, 169-181.

Reiner, E.J., Clement, R.E., Okey, A.B., Marvin, C.H., 2006. Advances in analytical techniques for polychlorinated dibenzo-p-dioxins, polychlorinated dibenzofurans and dioxin-like PCBs. Analytical and Bioanalytical Chemistry 386 (4), 791-806.

Schecter, A., Birnbaum, L., Ryan, J.J., Constable, J.D., 2006. Dioxins: an overview Environmental Research 101, 419-428.

Schoenmakers, P., Marriott, P., Beens, J., 2003. Nomenclature and Conventions in Comprehensive Multidimensional Chromatography. Coupling Matters. Lc.Gc Europe: Netherlands, Europe.

Semard, G., Adahchour, M., Focant, J.-F., 2009. Basic instrumentation for GC $\times$ GC In: Comprehensive Two Dimensional Gas Chromatography. Wilson \& Wilson's Comprehensive Analytical Chemistry, 55. Elsevier, Oxford, pp. 15-44.

Van Den Berg, M., Birnbaum, L.S., Denison, M., De Vito, M., Farland, W., Feeley, M., Fiedler, H., Hakansson, H., Hanberg, A., Haws, L., Rose, M., Safe, S., Schrenk, D., Tohyama, C., Tritscher, A., Tuomisto, J., Tysklind, M., Walker, N., Peterson, R.E. 2006. The 2005 world health organization re-evaluation of human and mammalian toxic equivalency factors for dioxins and dioxin-like compounds. Toxicological Sciences 93 (2), 223-241. 